\title{
Türkçe Web Sayfalarında Kadın Sağlığı İle İlgili Bilgilerin Değerlendirilmesi
}

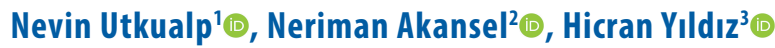

1Bursa Uludağ Üniversitesi, Doğum Kadın Hastalıkları Hemşireliği Anabilim Dalı, Bursa, Türkiye 2Bursa Uludağ Üniversitesi, Cerrahi Hastalıkları Hemşireliği Anabilim Dalı, Bursa, Türkiye

${ }^{3}$ Bursa Uludağ Üniversitesi, İç Hastalıkları Hemşireliği Anabilim Dalı, Bursa, Türkiye

Nevin Utkualp, Öğr. Gör. Dr. Neriman Akansel, Doç. Dr. Hicran Yıldız, Doç. Dr.

Illetişim:

Nevin Utkualp

Bursa Uludağ Üniversitesi, Doğum Kadın Hastalıkları Hemşireliği Anabilim Dalı, Bursa, Türkiye

Tel: +905366110496

E-Posta: nutkualp@uludag.edu.tr
ÖZET

Amaç: Bu çalışmanın amacı, kadınlara yönelik hazırlanmış olan web sayfalarının içeriklerinin değerlendirilmesidir.

Gereç ve Yöntemler: Bu çalışma, Türkiye'de en çok kullanılan arama motoru olan Google’da "kadın sağlığı”, “ kadın ve sağIık" anahtar kelimeleri kullanılarak yapılmıştır. Araştırmada tarama sırasında ilk sırada olan 25 web sayfası değerlendirmeye alınmıştır. Illgili web sayfalarında kadın sağıı̆ına yönelik bilgiler araştırmacılar tarafından literatür doğrultusunda hazırlanan kontrol listesi (22 madde) kullanılarak değerlendirilmiştir. Veriler SPSS 22.00 programında değerlendirilmiş, bulgular sayı ve yüzde olarak verilmiştir.

Bulgular: Web sayfalarının tamamında çeşitli hastalık nedenlerine yönelik bilgiler yer almaktadır. Yarıya yakınında (\%48) hastalıktan korunma yolları, tedavi ve yaşam kalitesi ile ilgili bilgiler mevcuttur. İncelenen web sayfalarının çok az bir oranında (\%28) güncelleme yapıldığı, bilgi içeriklerinin büyük bir kısmında da kaynak gösterildiği (\%72) belirlenmiştir. Web sayfalarının yarıya yakınında hekimler referans olarak yer almaktadır. Web sayfalarının $\% 74$ 'de konu ile ilgili resim mevcuttur, $\% 56$ 'sında konuyla ilgili farklı bir link bulunmaktadır ve $\% 52$ 'inde tıbbi terminolojinin kullanılmadığı görülmektedir.

Sonuç: Kadın sağlığı ile ilgili web sayfalarııın içeriği ve kapsamı farklııklar göstermektedir. Teknoloji ve bilimsel bilgi her gün hızla değiştiğinden web sayfalarında yer alan bilgilerin de hem güncel hem de doğru olması gereklidir. Web sayfalarının tasarımının iyi olması ve bilginin sistematik bir biçimde aktarıması kadın sağlığı ile ilişkin konularda bilgi edinmek isteyenlere ve kadın sağlığının gelişmesine katkı sunacağı düşünülmektedir.

Anahtar sözcükler: Kadın sağlığı, web sayfası, bilgi

\section{EVALUATION OF THE CONTENTS ON TURKISH WEBSITES (OR WEB SITES) RELATED TO WOMEN'S HEALTH}

\section{ABSTRACT}

Aim: The aim of this study is to determine the features of websites related to women's health.

Methods: Google Search engine was used to search for key words "women health", "women and health". The top 25 most searched websites were included in the study. A check list was developed by researchers according to the literature and used for evaluation of the web sites. Data were analyzed by using SPSS 22.00 and the results were given as numbers and percentages.

Results: The websites' contents were as follows: all websites included information related to diseases; almosthalf of them (48\%) included information on preventive methods, treatment of diseases and life quality. Only $28 \%$ of the websites were found to be updated and $72 \%$ of them included references. $44 \%$ of the web pages were developed by physicians. It was determined that $74 \%$ of the websites included pictures, $56 \%$ of them had links and $52 \%$ of them didn't use medical terms. Pregnancy, delivery, post pregnancy care and nutrition were among the common topics on the web pages.

Conclusion: Contents of the websites were varied. Information in the content should be accurate and up to date since the content of each topic changes as the technology and scientific knowledge changes gradually. The efficiency of the websites is important for the development of women's health especially the basic issues.

Keywords: Websites, women health, information
Gönderilme Tarihi : 18 Eylül 2018

Revizyon Tarihi : 12 Kasım 2018

Kabul Tarihi : 12 Kasım 2018 
G ünümüzde internet, bilgiye kolay ve hızlı ulaşabilmeyi sağladığından yaşamımızın önemli bir parçasını oluşturmaktadır. Bilim ve iletişim dünyasındaki hızlı gelişmeler (internet, intranet, sesli/görüntülü iletişim vb.) bilginin çok hızlı yayılmasına olanak sağlamakta, teknoloji ve sağlıktaki gelişmelerin izlenmesini olanaklı kılmaktadır. Bilgi ve iletişim teknolojilerinin eğitim amaçlı kullanılması yaygınlaştıkça e-öğrenme araçlarının sayısı ve çeşitliliğinde de bir artış gözlenmekte ve sanal ortam da buna yardımcı olmaktadır (1-2). İnternet, halk sağlığını korumada etkin bir bilgi kaynağıdır ve geleneksel eğitim yöntemlerine göre erişim kolaylığı nedeni ile avantajıdır $(3,4,5)$. Bunun yanı sıra web sayfalarının içeriklerinin kolayca güncellenebilmesi, erişim olanağı, fırsat eşitsizliklerinin giderilmesi, arz talep dengesinin sağlanması gibi pek çok olumlu katkısı da mevcuttur $(4,6)$.iletişim araçlarının toplumun davranış kalıplarını değiştirmek, bireylere bazı değerleri kazandırmak ve öğrenilenlerin içselleştirilmesini sağlamak açısından faydalı olduğu vurgulanmaktadır. Bilim, iletişim ve teknolojideki gelişmeler sayesinde medyanın büyük kitlelere kısa sürede ulaşması ve onları etkilemesi mümkün olmaktadır $(7,8)$.

İnternet, kadın sağlığı ile ilgili bilgilere ulaşım kolaylığı açısından değerlendirildiğinde, kadınların sağlıkla ilgili konulardaki gereksinimini karşılamada önemli rol üstlenebileceği öngörülmektedir $(8,9)$.Toplumda kadın sağlığını korunması ve geliştirilmesi aynı zamanda çocuğun, ailenin ve toplumun sağlığını da yakından etkilemektedir (10). Bu nedenle kadın sağlığı özel olarak ele alması gereken konuların başında gelmektedir. Dünyada ve ülkemizde kadın sağlığını etkileyen unsurlar arasında, kadının toplumsal cinsiyet rolü, kültür, eğitim düzeyi, sosyo-ekonomik düzey önemli belirleyiciler arasındadır (11). Kadın sağlığı sorunları ülkelerin gelişmişlik düzeyine göre farklılık göstermekle birlikte, toplumun kadın cinsiyetine biçtiği rol, beklentileri, kadının sağlık hizmetine ulaşmasını ve sağlığını önemli ölçüde etkilemektedir. Toplum içinde kadınların rolleri değiştikçe eğitime ilişkin gereksinimleri ve beklentilerinde de değişmeler olmaktadır. Kadınların kendi sağlık durumunu değerlendirebilmeleri, normal olmayan belirtileri fark ederek en kısa zamanda bir sağlık profesyoneline başvurmaları son derece önemlidir. Bununla birlikte kadınların merak ettikleri sorulara cevap bulmaları, karşılaştıkları sağlık sorunlarını etkin şekilde çözmeleri ve sorunlarla baş edebilmeleri yaşam kalitelerine önemli katkı sağlayacaktır $(12,13)$.

Web sayfaları sağlıkla ilgili çok farklı konularda ve kapsamda bilgi içeriğine sahip olduklarından, bilgi edinmek amacı bu sayfaları okuyan kişiler için önemli bir avantaja bazen de dezavantaja dönüşebilmektedir $(9,13)$. Bu nedenle kadının fiziksel ve psiko-sosyal sağlığının korunması ve geliştirilmesi, hastalıkların önlenmesi, koruyucu sağlık davranışlarının ve sağlık bilincinin geliştirilmesi amacıyla web sayfalarının güvenirliği ve işlevselliği son derece önemlidir $(13,14)$

Günümüzde kadınların ölüm nedenleri arasında sırasıyla dolaşım sistemi hastalıkları (\% 43,9), iyi ve kötü huylu tümörler $(\% 15,1)$ ve solunum sistemi hastalıkları $(\% 11)$ yer almaktadır. Bu konudaki farkındalığın artırılmasının ülkemizde kadın sağlığının geliştirilmesine büyük katkı sağlayacağı düşünülmektedir (15). Kadınların donanımlı olmasının, ailedeki diğer bireylerin ve özellikle çocukların eğitimi ve sağlığının korunması açısından olumlu sonuçları vardır (16). Zaman zaman hasta ve sağlık çalışanları arasındaki iletişimin sınırlı kalması, hastaların sormak istedikleri soruları sormaktan çekinmeleri onların internete başvurma eğilimini önemli ölçüde arttırmaktadır (17). Ancak web sayfalarının yüz yüze yapılması gereken sağlık eğitiminin yerini alacak bir seçenek olarak görmektense tamamlayıcı olarak kullanılmasının daha nitelikli bir seçim olacağı öngörülmektedir (18). Bu nedenle, kadın sağlığı ile ilgili web sayfalarının iyi tasarlanmış, içerdikleri bilginin doğru, anlaşılabilir ve güncel olması önemlidir (1119). Social Touch (2013) tarafından ülkemizde internetin sağlık amaçı kullanımını inceledikleri araştırmada; kadınların $(\% 58,7)$ interneti sağlıkla ilgili bilgi edinmek amaçlı kullandığı, \%60,88'nın internetteki forumları takip ettiğini belirlenmiştir (19).Bireylerin sağlık personellerinden bağımsız bir şekilde sağlıkla ilgili konularda web sayfalarını bir seçenek olarak görmeleri beraberinde bazı riskleri de getirmektedir. Özellikle Türkiye'de kadın sağlığı ile ilgili web sayfalarının değerlendirildiği çalışmalar oldukça sınırlıdır. Ülkemizde son yıllarda bu konu ile ilgili literatür incelendiğinde bir çalışmada 0-12 aylık bebek bakımı (20), başka bir çalışmada ise doğuma hazırlıkla ilgili web sayfalarının analizinin (21) yapıldığı çalışmalar dışında başka bir araştırmaya rastlanmamıştır. Bu çalışmanın amacı, kadınlara yönelik hazırlanmış olan web sayfalarının içeriklerinin değerlendirmektir.

\section{Yöntem}

Bu çalışma 15.01.2018 ile 15.02. 2018 tarihleri arasında Türkiye'de en çok kullanılan Google arama motoru kullanılarak kadın sağlığı ile ilgili web sayfaları incelenerek yapıldı. Google'da "kadın sağlığı"," kadın ve sağlık" anahtar kelimeleri kullanılarak yapılan arama sonucunda 40 web sayfasına ulaşıldı ve bunlar arasında ilk sırada yer alan 25 web sayfası incelendi. Web sayfalarının değerlendirilmesinde 
araştırmacılar tarafından ilgili literatür incelenerek geliştirilen ve 22 maddeden (web sayfalarının genel tasarımını ve içeriğini değerlendirmeye yönelik maddeler) oluşan değerlendirme formu kullanıldı. Veriler SPSS 22.00 programına girilerek elde edilen sonuçlar sayı ve yüzde olarak verildi.

\section{Çalışmanın Sınırlılıkları}

Çalışmanın sadece Türkçe web sayfalarının incelenerek yapılması ve en çok tıklanan ilk 25 sıradaki web sayfasının çalışmaya dahil edilmesi bu araştırmanının sınırlılıkları arasındadır.

\section{Bulgular}

Kadın sağlığı ile ilgili web sayfasının türünün yarıdan fazlasında (\%64) "com.tr" olduğu, bilgilerin \%44'ünün hekimler tarafından oluşturulduğu görüldü. Web sayfalarında yer alan bilgilerin büyük bir kısmının yazı büyüklüğünün (\%76) 12 punto olduğu belirlendi. İncelenen sayfalarda gebelik, doğum, doğum sonrası bakım, kadın ruh sağlığı, cilt ve saç bakımı sıklıkla en sık ele alınan konular arasındaydı (Tablo 1). Web sayfalarının içeriği incelendiğinde; kadın sağlığına ilişkin yeni tedavi yaklaşımlarına yer verildiği (\%80), kadın hastalıkları ile ilgili yeni tedavi önerisi ya da yönlendirme içerdiği (\%88),konunun aktarımında bir bütünlük olduğu (\%84), bilginin ilgi çekici bir şekilde aktarıldığı (\%88) ve tıbbi terminoloji içermediği (\%52) belirlendi. Web sayfalarının \%72'sinin tasarımında konu ile ilgili resimlerin yer aldığı, \%76'sında yazı rengi olarak siyah dışında bir renk seçildiği görüldü (Tablo 2).

\section{Tartışma}

Internet aracılığı ile edinilen sağlık bilgisinin kullanımı, doğrudan insan yaşamını etkilemesi nedeniyle oldukça önemlidir. Günümüzde, bilginin değerli olması ve zaman kısıtlılığı nedeni internet kullanımı giderek daha popüler hale gelmekte ve bireylerin internet aracılığı ile bilgi edinme eğilimi artmaktadır. Ancak bu eğilim, hızla değişen bilgi ve teknoloji dünyasında internet üzerinden elde edilen bilgilerin güvenilirliği konusundaki endişeleri de beraberinde getirmektedir $(22,23)$. Web sayfalarındaki bilgiler, belirli bir standarda uymamaları nedeni ile kendi içinde farklııklar göstermektedir. Çalışmamızda, web sayfalarının sadece \%72'sında tasarlayan kişinin kim olduğu belirtilmiştir. Kadın sağlığı ile ilgili web sayfalarının \%64'ü "com.tr" (commercial.Turkey=ticari.Türkiye) uzantılıdır ve sadece \%44'ünde bilgi içeriğinin bir hekim tarafından hazırlandığı görülmektedir. Web sayfalarında yer alan bilgi içeriklerinin sağlık alanında uzman kişiler tarafından tasarlanması ve güncellenmesinin, bu bilgilere ulaşarak
Tablo1. Türkçe Web sayfalarında kadın sağlığına ilişkin bilgilere ait özellikler

\begin{tabular}{|c|c|c|}
\hline Değişkenler & $\wedge n$ & $\%$ \\
\hline \multicolumn{3}{|l|}{ Internet site türü } \\
\hline com.tr & 16 & 64 \\
\hline net & 5 & 20 \\
\hline gov.tr & 3 & 12 \\
\hline org.tr & 1 & 4 \\
\hline \multicolumn{3}{|c|}{ Web sitesinin kimin tarafından tasarlandığı } \\
\hline Hekim & 11 & 44 \\
\hline Diğer & 6 & 32 \\
\hline Komisyon & 8 & 24 \\
\hline \multicolumn{3}{|l|}{ Yazı büyüklüğü } \\
\hline 12 punto & 19 & 76 \\
\hline 14 punto & 3 & 12 \\
\hline 10 punto & 2 & 8 \\
\hline 16 punto & 1 & 4 \\
\hline \multicolumn{3}{|c|}{ Web sayfalarındaki konu içerikleri } \\
\hline Genel kadın sağlığı * & 18 & 72 \\
\hline Doğum * & 17 & 68 \\
\hline Doğum sonrası & 17 & 68 \\
\hline Gebelik* & 15 & 60 \\
\hline Kadın ruh sağığı * & 13 & 52 \\
\hline Cilt ve saç bakımı* & 9 & 36 \\
\hline İyi huylu oluşumlar* & 7 & 28 \\
\hline Kötü huylu oluşumlar* & 7 & 28 \\
\hline Enfeksiyon* & 7 & 28 \\
\hline Cinsellik* & 4 & 16 \\
\hline Aile planlaması* & 1 & 4 \\
\hline
\end{tabular}

*Konu başı̆ı̆ı birden fazla Web sayfasında yer almaktadır

\begin{tabular}{|c|c|c|}
\hline Web sayfalarındaki bilgi içeriğinin kapsamı & $\begin{array}{c}\text { Evet } \\
\text { Sayı (n) }\end{array}$ & $\begin{array}{c}\text { Yüzde } \\
\text { (\%) }\end{array}$ \\
\hline $\begin{array}{l}\text { 1. Kadın hastalıkları ile ilgili yeni tedavi önerisi ya da } \\
\text { yönlendirme içeriyor mu? }\end{array}$ & 22 & 88 \\
\hline 2. Aktarılan bilgi ilgi çekici mi? & 22 & 88 \\
\hline 3. Konunun aktarımında bir bütünlük var mı? & 20 & 84 \\
\hline $\begin{array}{l}\text { 4. Kadın sağlığına iliş̧kin yeni tedavi yaklaşımlarına } \\
\text { yer verilmiş mi? }\end{array}$ & 19 & 80 \\
\hline 5. Sayfanın tasarımında renkler kullanıımış mı? & 18 & 76 \\
\hline 6. Yazı içinde görsellere/ resimlere yer verilmiş mi? & 17 & 72 \\
\hline 7. Hazırlayan kişi belirtilmiş mi? & 17 & 72 \\
\hline 8. Yazının güncelleme tarih var mı? & 16 & 68 \\
\hline 9. Yazının yayın tarihi belirtilmiş mi? & 15 & 64 \\
\hline 10. Sayfada tıklanma sayısı var mı? & 14 & 56 \\
\hline 11. Sayfada link yer alıyor mu? & 14 & 56 \\
\hline 12. Yazı tıbbi terminolojiden arındııımış mı? & 13 & 52 \\
\hline
\end{tabular}

kullanan kişilerin kendi sağlıklarının yönetiminde ortaya çıkabilecek olası riskleri ve eksiklikleri önleyebileceği düşünülmektedir $(24,25,26)$. Web sayfalarının içeriğinin güvenilirliği konusunda kullanııların farkındalıklarının arttırılması, bireylerin kendi sağlıkları ile ilgili değerlendirme yapabilmeleri ve doğru karar alabilmeleri açısından son derece önemlidir. Bunun yanında, web sayfalarının kendi sınırıııklarını (özellikle, sağlık kuruluşuna başvurulması 
gereken durumlar vb.) dürüst bir şekilde ortaya koyması ve bunları azaltmak için ilgili linklere veya referanslara yönlendirmesi kullanıcıların karşılaşabilecekleri risklerin azaltılması açısından önlemdir $(27,28)$. Çalışmamızda, incelenen web sayfalarının \%72'sinin tasarımına konu ile ilgili resimlerin yer aldığı ve \%76'sında yazı büyüklüğünün en az 12 punto olduğu görülmektedir. Web sayfalarının hazırlığında renk kullanımı ve yazı puntosunun büyüklüğü gibi ayrıntıların dikkatlice seçilmesi, içeriğinin anlaşılır ve net olması, dikkat çekiciliğinin sürdürülmesi kullanıcılar açısından önemlidir. Bunun yanı sıra web sayfalarının tıbbı terminoloji içermesi sağlıkla ilgili bir eğitimi olmayan kişilerce anlaşılırlığının azalmasına neden olabileceğini düşündürmektedir. İşleyen ve ark.(2005) yapmış olduğu bir çalışmada da Türkçe web sayfalarında yer alan sağlık bilgilerinin bunları hazırlayan hekimlerin akademik dil kullanmaları sebebi ile anlaşılırlığının düşük olduğunu saptanmıştır(27,28).

Benigeri ve Pluye (2003) tarafından yapılan bir çalışmada, web sayfalarındaki sağlık köşelerinde genel olarak kadın sağlığı ve gebelikle ilgili bilgiler bulunduğunu belirtilmektedir (23). Çalışmamızda, web sitelerinde en fazla yer alan konular; genel kadın sağlığı, doğum, doğum sonrası ve gebelik konularına yer vermesi açsından değerlendirildiğinde Benigeri ve Pluye (2003) çalışması ile benzerlik göstermektedir (23). Kadınlar, genellikle ekonomik güçlükler, ev ve çocuk bakımı ile ilgili konularda daha fazla sorumluluk üstlenmeleri, zamanlarının kısıtlı olması, içinde yaşadıkları toplumun kültür yapısı nedeni ile kendileri ile ilgili konuları ikinci planda bırakmaktadır. Bazı durumlarda da hem sağlık hizmetine ulaşmaları hem de sağlık hizmetinden yararlanmaları sınırlı düzeyde kalmaktadır (10). Web sayfalarında kadın sağlığına yönelik bilgilerin yer alması özellikle gebelik, doğum ve doğum sonrası gibi kadın yaşamının önemli bir parçası olan dönemlere ağırlık verilmesi önemli olmakla birlikte, bu süreç kadın yaşamında çok kısa bir dönemi kapsamaktadır. Bununla birlikte, gebelik kadınlar için önemli bir dönüm noktasıdır. Gebelik, doğum ve doğum sonrası dönem, kadının hem kendi vücudundaki fizyolojik değişimler hem de fetüsün sağlığı konusunda merak ettiği ve bilgi edinmek istediği konuların oldukça fazla olduğu bir süreçtir $(29,30,31)$. Çalışmamızda, web sayfalarının kadın sağlığına ilişkin yeni tedavi yaklaşımlarına ve kadın hastalıkları ile ilgili yeni tedavi önerilerine ya da yönlendirmelere yer verildiği görülmektedir. Artan bilgi ihtiyacını karşılamada ve gebe olan kadınların sanal ortamda kendileri gibi gebe olan kadınlarla iletişim kurmada, bilgi paylaşımında internet büyük role sahiptir $(10,15)$. Özellikle kadınların sağlık eğitimi gereksinimlerinin karşılanmasında internetin yeri yadsınamaz $(32,33)$. Ancak bu tür uygulamaların faydalarının yanı sıra yanlış bilgi edinmeye ve yanlış karar vermeye yol açabileceğini de öngörmek gereklidir. Diaz ve ark'nın (2002) çalışmasında, hekim veya hemşire dışında sağlık bilgisi için başvurulan kaynaklar arasında internet kullanımının ikinci sırada yer aldığı görülmektedir (7). Başka bir çalışmada ise, internet kullanıcılarının yaklaşık \%40'ının, sağlık bilgilerine erişim için interneti tercih ettikleri belirtilmektedir (32). Her on internet kullanıcısından sekizinin diyet, ilaç, sağlık sigortası, hekim ve hastaneler gibi sağlık konularında bilgi edinebilmek için interneti seçtikleri (30), özellikle ev hanımı ve yaşlı olan bireylerin sağlıkla ilgili konuları araştırmak için interneti tercih ettikleri görülmektedir (23). Vanzetta ve ark.(2012) İtalya'da Sağlık Bakanlığı'na tüm hastanelerin web sayfalarının incelendiği çalışmalarında, sayfaların \%58'inde sağlıkla (hastalık ve nedenleri, korunma önlemleri v.b) ile ilgili hiçbir bilginin bulunmadığını, web sayfalarının sadece \%22'sinde, kullanıcıların sağlık yönetimi konusunda bilgiye ulaşılabildiğini saptamışlardır (8). Bu durum internet web sayfalarının kapsamının ülkelere göre de değişiklik gösterdiğini düşündürmektedir. Özellikle maliyet etkinliği düşünüldüğünde sağlıkla ilgili hazırlanan web sayfalarının sadece bilgi aktarma dışında interaktif bir şekilde kullanımının sağlanması, video, resim gibi materyallerle görsel olarak zenginleştirilmesi, kullanıcıların birbiri ile iletişim kurabilecekleri forumlara yer verilmesinin bireylerin sağlığına önemli katkı sağlayacağı düşünülmektedir (18).

\section{Sonuç ve Öneriler}

Bu çalışmada değerlendirilen web sayfalarında güncelleme sayısının azlığı ve hazırlayanların yarıdan fazlasının sağlık profesyoneli olmaması yer alan bilgilerin güvenilirliği konusunda endişe yaratmaktadır. Web sayfalarından edinilen bilgilerin eksik veya yanlış olması sağlıkla ilgili risklerinin artmasına yol açacağından, toplumun ve özellikle kadınların sağlık okuryazarlığının artırılması, konuyla ilgili farkındalıklarının oluşturulması yönünde adımların atılmasının önemli olduğu düşünülmektedir. 


\section{Kaynaklar}

1. Isık O, Akbolat M. Bilgi Teknolojileri ve Hastane Bilgi Sistemleri Kullanımı: Sağlık Çalışanları Üzerine Bir Araştırma. Bilgi Dünyası 2010; 11:365-89.

2. Pellise' F, Sell P. Patient information and education with modern media: the Spine Society of Europe Patient Line. Eur. Spine Journal 2009;18: 395-401. [CrossRef]

3. Ergün M, Ergün E. Web Sitelerinin Çeşitli Özellikleri ve Eğitim Kurumları Web Sitelerine Yansımaları. Kuramsal Eğitim Bilim 2008;1:2-19.

4. Tuncer M, Taşpınar M. Sanal Ortamda Eğitim ve Öğretimin Geleceği ve Olası Sorunlar. Sosyal Bilimler Dergisi 2008;10:125-44.

5. Bozkurt A, Bozkaya M. Açık ve Uzaktan Öğrenmeye Yönelik Etkileşimli E-Kitap Değerlendirme Kriterlerinin Belirlenmesi, Yüksek Lisans Tezi, 2013.

6. Cetin I, Özhanlı Y. Surgical Patients' Features of Internet Use While Accessing Health Information. Kocaeli Sağlık Bilimleri Dergisi 2018;4:44-9.

7. Diaz J, Griffith R, James JN, Reinert S, MS, Friedmann P, Moulton A. Patients' Use of the Internet for Medical Information. J Gen Intern Medicine 2002; 17: 180-5.

8. Vanzetta M, Vellone E, De Marinis MG, Cavicchi I, Alvaro R. Online information supplied by Italian Hospitals and Local Healthcare Units: A Descriptive Research on their Compliance with the Guidelines Issued by the Italian Ministry Health. Ann Ig 2012; 24:507-16.

9. Verhoeks C,Teunissen D, Steenbergenand A, Lagro-Janssen A. Women's Expectations and Experiences Regarding e-Health Treatment: A Systematic Review. Health Informatics Journal 2017:0:1-17. [CrossRef]

10. Tözün M, Sözmen MK. Halk Sağlığı Bakışı ile Sağlık Okuryazarlığı. Smyrna Tıp Dergisi 2014:48-54.

11. Göktaş Y ve ark. Türkiye'de Eğitim Teknolojileri Araştırmalarındaki Eğilimler: 2000-2009 Dönemi Makalelerinin İçerik Analizi. Kuram ve Uygulamada Eğitim Bilimleri 2012;12: 177-99.

12. Lehnert JD, Ellingson MK, Goryoka GW, Kasturi R, Maier E, Chamberlain AT. Research Full Report: Use of Obstetric Practice Web Sites to Distribute Zika Virus Information to Pregnant Women During a Zika Virus Outbreak. Journal of Public Health Management and Practice 2017; 23: 608-13. [CrossRef]

13. Yirmibeşoğlu E, Öztürk AS, Erkal HŞ, Egehan İ. Kanser Hastalarının Bilgi Arayışında İnternet Kullanımı. İnönü Üniversitesi Tıp Fakültesi Dergisi 2015;12: 125-8.

14. Sinclair $P$, Kable A, Levett-Jones T. The Effectiveness of InternetBased e-Learning on Clinician Behavior and Patient Outcomes: A Systematic Review Protocol. JBI Database of Systematic Reviews and Implementation Reports 2015;13: 52-64. [CrossRef]

15. T.C. Aile ve Sosyal Politikalar Bakanlığı Kadının Statüsü Genel Müdürlüğü. Türkiye'de kadın. https://kadininstatusu.aile.gov.tr/ uygulamalar/turkiyede-kadin.

16. Berland GK, Elliott MN, Morales LS, Algazy Jl, Kravitz RL, Broder MS, et al. Health Information on The Internet: Accessibility, Quality, and Readability in English and Spanish. JAMA 2001; 285:2612-21.
17. Zülfikar H. Hastaların İnternet Kullanımı ve Elektronik Ortamdaki Bilgilerine Erişim Davranışları. F.N. Hemşirelik Dergisi 2014;22:46-52.

18. Demir Y, Gözüm S. Sağlık Eğitiminde Yeni Yönelimler; Web Destekli Sağlık Eğitimi DEUHYO ED 2011;4:196-203.

19. Türkiye'de İnternetin Sağlık Amaçlı Kullanımı. http://www. socialtouch.com.tr/Turkiye'de_internetin_saglik_amacli_kullanimi_ eylul2013.pdf.

20. Özkan Arslan H, Sardoğan C, Üşümüş G. 0-12 Aylık Bebeklerin Bakımı ile ilgili Türkçe Web Sitelerindeki Bilgilerin Güncellenmesi. KASHED 2017;3:7-21.

21. Çiçek Ö, Yenal K. Türkiye'de Doğuma Hazırlık Eğitimi ile Illgili İnternet Sayfalarının Analizi. STED 2016;25:131-5.

22. Fox S, Fallows D. Health Searches and Email Have Become More Commonplace, but There is Room For Improvement in Searches and Overall Internet Access. Pew Internet and American live project: Online life report. 2003 Jul 16. http://www. pewinternet. org/ reports/pdfs/PIP_Health_Report_July_2003.pdf.

23. Benigeri M, Pluye P. Shortcomings of Health Information on the Internet. Health Promotion International Journal 2003;18:381-6.

24. Kiley R. Does the Internet Harm Health? British Medical Journal 2002;26: 235-41.

25. Özpınar A, Kazaskeroğlu E, Özgün Ö. Bilgiye Erişim, Paylaşım ve Bilgi Teknolojileri Alanında Etik Olmayan Davranışlar ve Sebepleri. Ağ ve Bilgi Güvenliği Sempozyumu, Ankara, 25-26 Kasım 2011.s.3-6.

26. Mumcu G, Koksal L, Sisman N, Çatar O. Continuing Medical Education and e- Learning for Health Professionals. Clinical and Experimental Health Sciences 2011;1:74-8.

27. İşleyen F, Gülkesen KH, Zayim N. Türkçe Web Sitelerinde Sunulan Sağlık Bilgisinin Anlaşılırlığı. Ulusal Tıp Bilişimi Kongresi, Antalya, 1720 Kasım 2005

28. D'alessandro D M, Kingsley P, Johnson-West J. The Readability of Pediatric Patient Education Materials on the World Wide Web. Archives of Pediatrics \& Adolescent Medicine 2001;155:807-12.

29. Zingmond DS, Lim YW, Ettner SL, Carlisle DM. Information Super Highway or Billboards by the Roadside? An Analysis of Hospital Web Sites. Western J Med 2001;175:385-91.

30. Aygün CS. İnternet ve Etik: Örnek Uygulama Alanı Olarak Sağlık İletişimi. XII.Türkiye'de İnternet Konferansı, Ankara, 8-10 Kasım 2007. s.292-305.

31. Wasserman M, Baxter NN, Rosen B, Burnstein M, Halverson AL. Systematic Review of Internet Patient Information on Colorectal Cancer Surgery. Diseases of The Colon \& Rectum 2014; 57: 64-9. [CrossRef]

32. Eysenbach $\mathrm{G}$. The Impact of the Internet on Cancer Outcomes. CA: A Cancer Journal for Clinicians 2003;53:356-71

33. Başak F, Başak S, Öztürk K. Devlet Hastaneleri Web Sitelerinin Değerlendirilmesi. V. Tıp Bilişimi Kongresi, Antalya, 13-16 Kasım 2008. s.75-80 